\title{
O Adoecimento, o Tratamento e a Relação Paciente-Médico- Cuidador Segundo a Criança Hospitalizada
}

\section{Illness, Treatment and the Patient-Doctor-Caregiver Relationship According to the Hospitalized Child}

\author{
Carine da Silva Budzyn' (orcid.org/0000-0003-3180-6595) \\ Viviane Ziebell de Oliveira² (orcid.org/0000-0001-6126-0605)
}

\begin{abstract}
Resumo
Este estudo buscou descrever como a criança enferma compreende seu adoecimento, tratamento e relação pacientemédico-cuidador em internação pediátrica. Participaram seis crianças hospitalizadas, de oito a 11 anos, que responderam à entrevista semiestruturada e Procedimento Desenho-Estória com Tema (PDE-T), sendo o material gravado, transcrito e submetido à análise qualitativa. O conteúdo revelou o impacto emocional e social do adoecimento e experiência de internação, vista como restritiva e punitiva, mas também como espaço de brincar e se relacionar com os pares. As crianças mostraram pouca participação na relação paciente-médico-cuidador, reconheceram seus médicos como atuantes no tratamento e a mãe, principal cuidadora, como mediadora dessa relação e fonte de apoio psicológico. A partir dos resultados, assinala-se a importância de intervenções psicossociais e multidisciplinares que auxiliem as crianças em suas demandas e favoreçam sua postura ativa nessa relação triádica, tão significativa no processo de cuidado em saúde da criança.
\end{abstract}

Palavras-chave: Criança hospitalizada. Relação médico-paciente-cuidador. Relação médico-paciente. Relação mãecriança. Pediatria.

\begin{abstract}
This study aimed to describe how the sick child understands hi illness, treatment and the patient-doctor-caregiver relationship in pediatric hospitalization. Six hospitalized children from eight to 11 years participated, who answered the semi-structured interview and the Desenho-Estória com Tema (PDE-T) procedure, and the material was recorded, transcribed and submitted to qualitative analysis. The content revealed the emotional and social impact of illness and hospitalization experience, seen as restrictive and punitive, but also as a space for playing and relating to peers. The children showed little participation in the patient-doctor-caregiver relationship, acknowledged their doctors' active role in their treatment and their mothers', main caregiver, as a mediator of this relationship and source of
\end{abstract}

\footnotetext{
${ }^{1}$ Hospital de Clínicas de Porto Alegre, Porto Alegre, Brasil. E-mail: cbudzyn@hotmail.com.

${ }^{2}$ Hospital de Clínicas de Porto Alegre, Porto Alegre, Brasil. E-mail: vzoliveira@hcpa.edu.br.
} 
psychological support. From the results, is highlighted the importance of psychosocial and multidisciplinary interventions that help children in their demands and favor their active stance in this triadic relationship, so significant in the child's care process.

Keywords: Hospitalized children. Doctor-patient-caregiver relationship. Doctor-patient relationship. Mother-child relationship. Pediatrics. 


\section{Introdução}

O adoecimento físico e a decorrente internação são experiências marcantes na vida da criança. Para além do corpo doente, o psiquismo e suas relações com o meio também se veem ameaçados nessas circunstâncias, pois a criança pode experimentar insegurança e desamparo, e se perceber afastada de sua vida social e de seus hábitos cotidianos (Nigro, 2004).

Ao longo dos anos, estudos têm evidenciado o aspecto ameaçador e desestruturante dessas experiências para crianças com diferentes enfermidades (Anton \& Piccinini, 2011; Aquino, Conti \& Pedrosa, 2014). O grau do impacto sofrido irá depender de diversos fatores: nível de desenvolvimento e características psíquicas da criança, dinâmica familiar; sintomatologia, gravidade, visibilidade e duração da doença; tipos de intervenções médicas necessárias, como procedimentos invasivos, tratamentos prolongados e recorrentes internações (Castro, 2007). Esse tipo de vivência por um ego infantil, em processo de estruturação, demandará um redirecionamento dos investimentos libidinais - dos objetos para o próprio eu (Freud, 1914/2011); assim como a qualidade das primeiras experiências infantis, baseadas em um vínculo mãe-bebê harmonioso e em um ambiente facilitador, será fundamental para o adequado desenvolvimento psíquico da criança (Winnicott, 1956/2000), e incidirá na maneira como enfrentará seu adoecimento e internação. Portanto, a existência de uma adequada relação entre a criança enferma e o adulto cuidador pode auxiliá-la na elaboração dessas experiências.

A relação da criança com o adulto se configura como importante recurso interpessoal ao possibilitar à criança modificar seu estilo de vida para que possa assumir sua própria capacidade de enfrentar a vivência hospitalar (Castro \& Thomas, 2012). Em Pediatria, se estabelece minimamente entre criança, médico e cuidador/família e consiste em um elemento significativo no processo de cuidado, podendo influenciar na compreensão do diagnóstico, na adesão ao tratamento e no prognóstico do paciente (Kohlsdorf \& Costa Junior, 2016; Sleath et al., 2012). Nesse complexo universo relacional, encontram-se operando dinamicamente fatores oriundos dos componentes da tríade e do setting hospitalar, caracterizado como intrusivo, não privativo, limitador e atemporal (Perosa, Gabarra, Bossolan, Ranzani \& Pereira, 2006; Simonetti, 2008). Coexistem expectativas e esperanças de ambos os lados, sendo a dependência e a confiabilidade termos pertencentes ao cuidado (Schmidt \& Mata, 2009). Empatia, atenção, assertividade, compreensão do contexto sociocultural, da dinâmica familiar, do brincar, da atividade social e escolar da criança constituem aspectos essenciais a essa relação (Barletta, Gennari \& Cipolotti, 2011; Kohlsdorf \& Costa Junior, 2013).

No entanto, a literatura tem assinalado a presença de dificuldades, principalmente nos aspectos comunicacionais, uma vez que a relação estaria ocorrendo entre médico e cuidador, excluindo a criança da comunicação e 
interação (Cristo \& Araújo, 2013, 2015). Estudos que investigaram a temática também têm priorizado profissionais e familiares como fontes de informação. Conforme revisão de 118 publicações científicas sobre comunicação triádica em pediatria (entre 2000 e 2012), realizada por Kohlsdorf e Costa Junior (2016), a maioria dos estudos sobre o tema utilizou informantes adultos (médicos e cuidadores) em detrimento das crianças. No entanto, no decorrer do desenvolvimento, as crianças vão se mostrando capazes de expressar sintomas e comportamentos de autocuidado e de perceber conteúdos ocultados pelos adultos (Aberastury, 1984). Especialmente no período da latência, encontram-se aptas a compreender e explicar os fenômenos com base na realidade; há um importante acréscimo de domínio e autonomia; e passam a desenvolver relações interpessoais mais elaboradas (Ferreira \& Araújo, 2012; Freud, 1905/2016; Souza, 2014). O brincar, assim como o desenho, tornam-se formas de expressão de conteúdos manifestos e latentes relacionados à realidade da criança (Klein, 1932/1981; Winnicott, 1975). O desenho, meio de comunicação com a criança e seu mundo, configura-se como mediador das relações que são estabelecidas com o paciente infantil (Trinca, 1997). Trata-se de um instrumento amplamente utilizado em Psicologia, inclusive em âmbito hospitalar (Martão, 2013; Prudenciatti, Tavano \& Neme, 2013), pois permite que projete sua experiência interna no mundo externo (Menezes, Moré \& Cruz, 2008). Assim, a criança pode organizar informações e processar experiências, construindo relações e símbolos, desenvolvendo conceitos e representando suas singularidades (Aiello-Vaisberg \& Ambrósio, 2013).

Diante do exposto, o estudo se justifica pela complexidade do tema abordado, por sua relevância no cenário da saúde da criança e pela carência de pesquisas acerca da compreensão infantil sobre as relações na internação pediátrica. Assim sendo, o presente estudo visou descrever como a criança enferma compreende seu adoecimento, tratamento e relação pacientemédico-cuidador em internação pediátrica.

\section{Método}

\section{Participantes}

Participaram do estudo seis crianças, de oito a 11 anos, internadas em enfermaria pediátrica de hospital universitário do sul do país para tratamento de quadros clínicos agudos ou crônicos que atenderam aos seguintes critérios de inclusão: idade entre sete e 12 anos; estado clínico estável, conforme definição médica; apta a desenhar e se comunicar verbalmente; acompanhada de um cuidador. Foram excluídas as que apresentaram comprometimento neurológico e/ou cognitivo clinicamente observável. As características sociodemográficas, da doença e da internação se encontram agrupadas na Tabela 1. As crianças foram identificadas pela letra $\mathrm{C}$, seguida do número correspondente à ordem de participação no estudo, a fim de resguardar sua identidade e de suas famílias. 
Tabela 1. Características sociodemográficas, da doença e da internação das crianças

\begin{tabular}{|c|c|c|c|c|c|c|c|}
\hline & $\begin{array}{l}\text { Idade } \\
\text { (anos } \\
\quad) \\
\end{array}$ & $\begin{array}{l}\text { Sexo } \\
*\end{array}$ & $\begin{array}{c}\text { Escolaridad } \\
\mathrm{e} \\
(\text { ano }) \\
\end{array}$ & Diagnóstico & $\begin{array}{c}\text { Permanênci } \\
\text { a } \\
\text { (dias) }^{* *}\end{array}$ & $\begin{array}{l}\text { Internaçõe } \\
\text { s Prévias }\end{array}$ & $\begin{array}{c}\text { Principal } \\
\text { Cuidado } \\
\mathbf{r} \\
\end{array}$ \\
\hline $\begin{array}{l}\mathrm{C} \\
1\end{array}$ & 8 & $\mathrm{M}$ & $3^{\circ}$ & $\begin{array}{l}\text { Artrite reumatoide } \\
\text { juvenil }\end{array}$ & 8 & Sim & Mãe \\
\hline $\begin{array}{l}\mathrm{C} \\
2\end{array}$ & 10 & $\mathrm{~F}$ & $5^{\circ}$ & $\begin{array}{l}\text { Esferocitose } \\
\text { hereditária/pancreatit } \\
\text { e aguda }\end{array}$ & 20 & Sim & Mãe \\
\hline $\begin{array}{l}C \\
3\end{array}$ & 8 & $\mathrm{~F}$ & $3^{\circ}$ & $\begin{array}{l}\text { Febre não } \\
\text { especificada e } \\
\text { constipação }\end{array}$ & 7 & Sim & Mãe \\
\hline $\begin{array}{l}\mathrm{C} \\
4\end{array}$ & 8 & M & $3^{\circ}$ & $\begin{array}{l}\text { Atresia de vias } \\
\text { biliares }\end{array}$ & 7 & Sim & Mãe \\
\hline $\begin{array}{l}C \\
5\end{array}$ & 11 & M & $4^{\circ}$ & Lúpus eritematoso & 11 & $\operatorname{Sim}$ & Mãe \\
\hline $\begin{array}{l}C \\
6 \\
\end{array}$ & 9 & $\mathrm{~F}$ & $3^{\circ}$ & Hepatite autoimune & 10 & Sim & Mãe \\
\hline
\end{tabular}

* M: masculino; F: feminino

** $\mathrm{Na}$ realização da coleta dos dados.

\section{Delineamento,}

\section{Procedimentos,}

\section{Instrumentos e Aspectos Éticos}

Trata-se de um estudo de abordagem qualitativa, transversal, de caráter exploratóriodescritivo (Creswell, 2010). Depois de aprovada pelo Comitê de Ética em Pesquisa do Hospital de Clínicas de Porto Alegre (CAEE: 67442117.8.0000.5327), a coleta dos dados, de junho a agosto de 2017, iniciou com consultas aos prontuários de crianças internadas, a fim de selecionar as que atenderiam aos critérios estabelecidos (amostra por conveniência). Às crianças selecionadas e seus responsáveis, foi realizada leitura e assinatura de Termo de Consentimento Livre e Esclarecido (TCLE) e preenchimento da Ficha de Identificação, contendo informações sociodemográficas, da doença e da internação das crianças, caracterizando as participantes. Em sala de atendimento da Psicologia na Unidade de
Internação Pediátrica, depois do estabelecimento de rapport, foi realizada entrevista semiestruturada com a criança, investigando sua compreensão sobre a doença, o tratamento e a relação paciente-médico-cuidador.

Posteriormente, foi aplicado o Procedimento de Desenho-Estória com Tema (PDE-T) (Aiello-Vaisberg, 1997), instrumento adaptado do Procedimento de Desenho-Estória (D-E) (Trinca, 1997), que pode ser aplicado individual ou coletivamente, em diferentes faixas etárias, o qual possibilita a expressão da subjetividade associada a uma temática específica. Neste estudo, o PDE-T foi utilizado como instrumento complementar à comunicação verbal das crianças, tendo em vista que, na faixa etária estudada, a expressão gráfica se constitui como importante meio de acesso ao psiquismo infantil (Ferreira \& Araújo, 2012).

Mediante disponibilização de material gráfico (folha de papel em branco, lápis preto $\mathrm{n}$. 
2 e caixa de lápis de cor com 12 unidades), foi solicitada às crianças a elaboração de dois desenhos, conforme as seguintes instruções: 1. "Desenhe uma criança no hospital que está sendo atendida por um(a) médico(a)"; e 2 . "Desenhe uma criança no hospital que está sendo cuidada por uma pessoa". Optou-se pela realização dos dois desenhos, a fim de se obter informações mais detalhadas a respeito de cada uma das diferentes situações. Foram disponibilizados lápis coloridos às crianças, conforme sugerem Corbett, Ambrosio, GalloBelluzzo e Aiello Vaisberg (2014) e Prudenciatti, Tavano e Neme (2013). Ao término de cada desenho, foi requisitado à criança que contasse uma história sobre ele, atribuindo-lhe um título. Enquanto contava a história, foram realizadas intervenções para esclarecer e aperfeiçoar a narrativa elaborada pela criança. $\mathrm{O}$ processo de coleta dos dados durou aproximadamente 60 minutos e ocorreu em dois encontros. As entrevistas e relatos provenientes do PDE-T foram gravados em áudio e posteriormente transcritos na íntegra para análise do material.

As entrevistas transcritas foram submetidas à análise de conteúdo qualitativa (Laville \& Dionne, 1999). Foi utilizado o modelo misto de análise, com categorias construídas a priori, baseadas nas questões da entrevista, enquanto outras derivaram da leitura desse material. Foram realizadas sucessivas leituras por dois colaboradores, de forma independente, a fim de alocar as falas e verificar a pertinência dos conteúdos alocados. Em caso de dúvidas, buscou-se o consenso entre os colaboradores. Para a análise do material do PDE-T, primeiramente, foi realizada leitura guiada pela atenção flutuante. $\mathrm{Na}$ sequência, atentou-se ao que recebeu destaque para proceder à interpretação e foi realizado levantamento de hipóteses para compreender a subjetividade que se configurava (AielloVaisberg, 1997). Aqui, indo ao encontro do postulado no instrumento de origem (D-E), buscou-se analisar conteúdos emocionais abrangentes relacionados à relação pacientemédico-cuidador na internação pediátrica, não enfocando a exploração do imaginário coletivo das crianças sobre o referido tema. O material derivado dessa análise foi incluído nas categorias emergentes.

\section{Resultados}

Da análise dos conteúdos trazidos pelas crianças, emergiram três categorias temáticas: "O adoecimento e suas implicações", "A experiência de internação" e "A relação paciente-médico-cuidador", que são apresentadas a seguir com trechos ilustrativos dos relatos derivados das entrevistas e do PDET. Depois da apresentação das categorias, os achados foram discutidos segundo a literatura.

\section{O Adoecimento e suas Implicações}

Esta categoria aborda o entendimento das crianças participantes sobre suas enfermidades e tratamentos e o impacto físico, emocional e social despertado ao se deparar com o adoecer. Em alguma medida, os pacientes infantis souberam informar aspectos de sua condição de saúde e, ao discorrerem sobre suas doenças, demonstraram variados graus de 
compreensão. C1 e C3 referiram apenas sintomas, ao passo que as demais nomearam seus diagnósticos e mostraram algum conhecimento, ainda que, por vezes, incipiente.

Eu não estava doente, estava com dor. (C1)

Só sei que tenho cirrose biliar. Não sinto nada. (C4)

Tenho hepatite medicamentosa. Meu fígado não vai mais produzir vitaminas e, então, todos os dias eu tenho que tomar vitaminas, e ele rejeita. (C6)

De maneira geral, as crianças mostraram conhecer os cuidados a serem executados em seus tratamentos, conforme os enumerados por C2, C4, C5 e C6: usar medicamentos, cuidar da alimentação, evitar bater determinado órgão ou a exposição solar excessiva e realizar cirurgia. Contudo, foram observadas dificuldades no autocuidado e adesão ao tratamento em C5 antes da atual internação: "Não passava protetor, não comia e não tomava remédio, colocava fora."

A participação de terceiros na adesão ao tratamento também foi relatada pelas crianças. Além da mãe, o pai, o padrasto, as enfermeiras e as professoras também foram mencionadas como figuras de cuidado: "É fácil quando os outros já estão sabendo do teu problema, então, não fica muito difícil de eu conseguir me cuidar" (C2).

Ao descreverem sintomas físicos, evidenciaram manifestações clínicas repentinas e/ou que impossibilitaram a realização de atividades cotidianas, revelando o abalo ocasionado por estes em suas vidas: "Foi de um dia pro outro. Eu estava de noite bem, e acordei muito amarela" (C2). "Não conseguia andar. Não fui nem pra aula, porque eu estava com dor" (C1).

A vivência do adoecimento despertou sentimentos e suscitou defesas perante $\mathrm{O}$ sofrimento experimentado pelas crianças. $\mathrm{Na}$ leitura do material produzido por elas, foi observado que abordaram direta ou indiretamente seus medos e expressaram ansiedade, angústia, tensão, preocupação, culpa, insegurança e impotência. Utilizaram ainda regressão, formação reativa e racionalização como mecanismos defensivos diante da situação estressante. Ao falar sobre seu diagnóstico, C5 trouxe sentimentos associados: "Essa doença para mim é a coisa mais horrível que aconteceu e uma pessoa poderia ter. Vou ser o único que não pode ir ao sol."

C4, ao relatar situação de cirurgia em seu desenho-estória ( $A$ alta do menino), referiu sentimentos maternos, sugerindo culpa por estar doente: “A mãe se sentia triste, porque ela não queria que cortassem a cabeça do filho dela."

Em seus desenhos-estórias, as crianças puderam ilustrar seus sintomas nos personagens, sendo que C1, C4 e C6 "ensaiaram" sua cessação. C6 representou situação de personagem que obtinha a cura de sua enfermidade (Figura 1). 
Figura 1. O menino com dor de cabeça

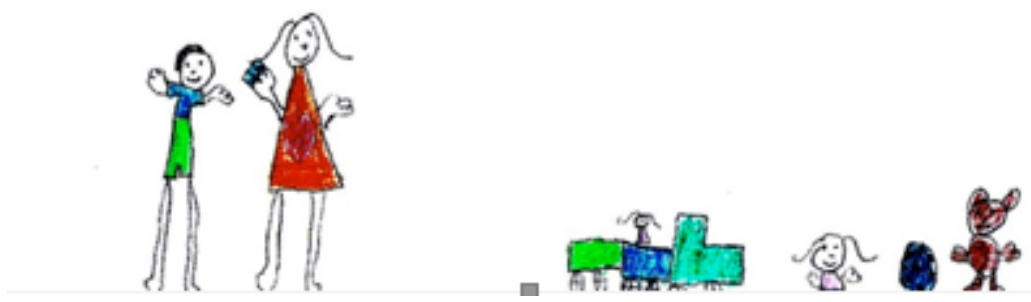

"A mulher está dando o remédio para o menino [...] pra ele não ter mais a doença."

\section{A Experiência de Internação}

Nesta categoria, foram contempladas memórias, sentimentos e reações afetivas diante da experiência de internação das crianças participantes, buscando apresentar como compreendem, se sentem e se relacionam perante esta. Todas as crianças referiram internações prévias, ocorridas em seus primeiros anos de vida e/ou recentemente para investigação diagnóstica. Para C2, C4 e C5, que receberam diagnósticos de doença orgânica crônica quando menores, essas internações foram recorrentes ao longo dos anos. Já, as internações prévias de C1 e C3 foram motivadas por manifestações clínicas agudas: "Quando eu era pequena, até os meus quatro anos, eu fiquei bastante vezes internada, porque eu tinha muito problema de urina" (C2). "Eu só me lembro de estar com muita dor no ouvido, aí eu fui pra outro hospital" (C3).

As vivências recentes foram lembradas pelas crianças, como C6, que havia sido internado em outro hospital meses antes. Lá, revelou que sua experiência foi desagradável, invasiva e temerosa, diferentemente da atual: "Era ruim. Eles tiravam quase todos os dias o sangue de quem estava lá. Aqui, tem mais recursos, e eu posso sair muito boa e nunca mais voltar para cá, não furar a veia."

Em relação à atual internação, observou-se que as crianças vivenciaram-na com algumas semelhanças quanto aos afetos despertados, que causou sentimentos de confinamento e tédio, impossibilitando a realização de atividades prazerosas. Conforme referido por C4, "Está sendo ruim. Não gosto de ficar internado. Não é bom ficar preso no soro, porque não tem nada para fazer na cama."

Houve também ambivalência despertada por essa vivência, quando perceberam a internação como espaço de reclusão, mas que também permitia momentos de brincadeiras. A internação foi ainda referida como circunstância de tratamento, que também possibilitou brincar em espaço recreativo.

Foi só um pouquinho chatinho, porque eu não sabia o que fazer. Mas, não foi chato. Eu jogava uns jogos com a minha mãe e jogava no celular. (C2)

Está bom. Eu estou gostando, porque tem esse negócio ali pra brincar [recreação]. Então, eu não fico trancada dentro do quarto. Eu brinco no computador, depois eu mexo no videogame, depois eu pinto. (C3) 
Em seus desenhos-estórias, as crianças representaram espaços da enfermaria (quarto, corredores, recreação) e expressaram sentimentos associados à experiência de internação. O sentimento de restrição e exclusão se evidenciou ao retratarem o quarto com a porta fechada, e em trecho da história elaborada por C2, sobre uma menina que apresenta comprometimentos. A mesma criança, em seu segundo desenho-estória, também retratou o brincar como movimento de saúde, ao contar a história de um menino que vivencia internação prolongada:

Talvez, ela não esteja tão bem, porque ela não pode sair da cama. Ela pode estar se sentindo presa. Não pode ir à praia, não pode fazer uma coisa que ela gostaria de fazer - "O cuidado de uma paciente".

Aqui, ele está feliz, porque pode se movimentar e pode brincar - "A brincadeira que não tem fim".

Observou-se também identificação das crianças com seus pares durante período de internação, ao incluí-los em seus desenhos e histórias. C5 ilustrou seu colega de quarto, e C6 pareceu se tranquilizar ao conhecer outras crianças acompanhadas pela mesma equipe de saúde.

Eu no meu quarto e duas enfermeiras cuidando de mim e do meu amigo. Minha pressão está bem, a dele também. A temperatura está boa, mas vai ter que ficar mais alguns dias - "As enfermeiras legais". (C5)

Lá, tem umas criancinhas que podem viver normal, podem ir para a escola, voltar para a casa, aí me senti bem. (C6)

\section{A Relação Paciente-Médico-Cuidador}

Esta categoria engloba a perspectiva das crianças sobre seu médico e a relação estabelecida com esse profissional no período de internação, assim como a participação de seu cuidador nesse âmbito relacional. Também foram incluídos aspectos relatados pelas crianças de sua relação com o cuidador devido à influência exercida nesse contexto.

Quando questionadas sobre seu médico, as crianças mencionaram profissionais que as atenderam na atual internação e/ou em consultas ambulatoriais prévias realizadas no hospital. Diferenciando-se destas, C1 referiu nome de pediatra que o acompanha regularmente em seu município. C2, C3 e C6 conheceram os profissionais na atual internação, ao passo que os médicos de C4 e C5 já os acompanhavam sistematicamente no hospital, em ambulatório e internações ao longo dos anos.

As crianças também referiram acompanhamento por mais de um médico durante a internação. C2 e C5 apontaram ser assistidas, simultaneamente, por médicos de diferentes especialidades, como cirurgia pediátrica e gastropediatria. C3 (em seu desenho-estória) e C6 assinalaram a ocorrência de trocas de profissionais características em um hospital-escola:

Os médicos foram ver as meninas. Os mesmos médicos, mas, às vezes, troca. [Uma menina] está com muita dor. Eles falaram que vão tentar ver isso. - "Duas meninas no hospital". (C3)

$\mathrm{Na}$ verdade, fiquei com outra doutora e, depois, com um doutor. Ele não é mais 
meu doutor, é de outra pessoa. Daí, a amiga da doutora fica comigo agora. (C6)

Por meio de seus relatos e desenhosestórias, as crianças representaram seus médicos como profissionais que examinam, tratam, cuidam e brincam: "Ele é bem divertido. Faz bastante piada" (C2). "Acho ele bom. Faz cosquinhas na minha barriga" (C4). "Eu acho que eles são importantes, pelo que estão fazendo por mim" (C5).

Em seu desenho-estória, C6 representou suas médicas examinando e tratando sua personagem. (Figura 2).

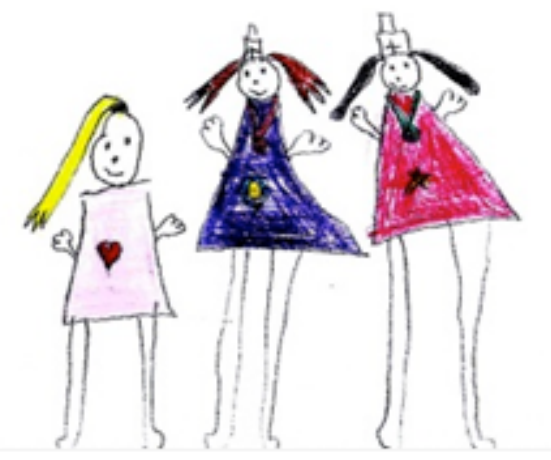

“A menina estava mal, porque estava doente. Deram remedinho, examinaram ela. Agora, ela está bem."

As crianças retrataram os encontros com seus médicos tanto em contexto de internação (C1, C2, C4, C6) quanto em de ambulatório (C3 e C5). Em suas produções, tenderam a apresentar postura passiva e contemplativa na relação, mostrando pouca iniciativa e necessitando do auxílio de terceiros. Entretanto, em seu desenho-estória, C5 se colocou ativo e autônomo na relação com sua médica, questionando e buscando assimilar as orientações transmitidas.

Eu estou conversando com a doutora. Ela está falando dos meus cuidados, que tenho que tomar os remédios, passar bastante protetor para viver bastante. Falei que é verdade que tenho que viver e tomar remédio. A doutora foi ver os remédios, lá, e me entregou - “A consulta mais legal".

Aspectos comunicacionais da relação também foram aludidos pelas crianças. Algumas referiram perguntar suas dúvidas ao seu médico, mostrando querer saber sobre sua doença e tratamento: "Ele [médico] me disse que eu ia ter que fazer cirurgia de vídeo, que eu não ia ficar acordada, e que eu não vou sentir dor na hora de fazer a cirurgia" (C2). "Eu perguntei se eu ia fazer outra biópsia, pois tenho muito medo" (C6).

Outras relataram que seus médicos lhes explicaram sobre sua condição clínica, contudo revelaram nem sempre compreender o que lhes foi comunicado: "Entendo só um pouquinho" 
(C3). "Começam a explicar, porque não entendo quase nada da minha doença" (C5).

C5 referiu não questionar sua médica sobre seu diagnóstico por vergonha ou por temer nova internação. Porém, mostrou interesse em conhecer mais sobre sua doença: "Eu tenho vergonha de todos. Eu fico envergonhado de perguntar, de falar. Eu queria saber mesmo o que ela afetava mais no corpo. Uma vez, eu acho que afetou meus pulmões" (C5).

C4 mencionou que seu médico explicou sobre sua condição, porém se direcionando a sua mãe: “[O médico] só fala com a minha mãe. [...] como todos os médicos, até quando eu vou embora."

C5 e C6 referiram que suas médicas lhes contaram sobre o diagnóstico. As demais crianças souberam por meio de suas mães: "Eu fiquei sabendo porque a minha mãe me contava que eu tinha o problema" (C2). "Eu só vejo a minha mãe falar" (C4).

Nesse contexto relacional, a mãe surgiu como principal cuidadora em relação às demandas do adoecimento e da internação, bem como importante intermediária na relação da criança com o médico, traduzindo aspectos do diagnóstico e do tratamento. As mães foram incluídas no primeiro desenho-estória, que abordava a relação médico-paciente, representando assim a importância dessa figura na relação criança-médico-cuidador. Elas relataram que suas mães ocupam importante lugar em seus tratamentos, que as orientam nos cuidados de saúde, auxiliando-as na administração dos medicamentos, na alimentação e na proteção contra quedas.
Ela faz comida. Me dá remédio. (C1)

A minha mãe quer que eu coma bem e não ande de pés descalços. (C3)

[A mãe] me ajuda a levantar quando cair. Se cair, colocar as mãos no chão, pra mim não bater a barriga. (C4)

É a essa figura que recorrem quando estão doentes: “Chama a mãe, e a mãe nos leva pro médico" (C3).

A mãe é vista como fonte de apoio psicológico no enfrentamento das adversidades do adoecimento, mostrando-se "continente" diante das angústias dos filhos nessa situação. C4, em desenho-história, representou mãe e filho: "Eles estão no quarto do hospital. Os dois estão dando carinho um pro outro. Estão se sentindo felizes porque ganharam alta - 'A alta do menino."”

No caso de C2, observou-se identificação entre filha e mãe devido ao mesmo diagnóstico.

Ela me fala que eu não tenho que me sentir triste, porque não posso fazer alguns esportes. [...]. Ela não me mentiu que eu ia fazer a minha cirurgia. Eu tenho problema do baço, ele é hereditário, é de mãe pra filha. A minha mãe já tirou o baço [...] ela nunca mais teve problema, e eu vou tirar agora o meu.

Entretanto, quando a mãe não tem condições de oferecer esse suporte, pode impactar significativamente no psiquismo da criança e, consequentemente, na adesão ao tratamento, conforme sugerido no caso de C5. No desenho-estória sobre a relação com o cuidador, retratou sua mãe como uma figura pouco envolvida no cuidado: "Ela [mãe] me leva 
pra sair, me deixa jogar, e gosta de ajudar de vez em quando. A minha mãe está dormindo - 'As enfermeiras legais."”

\section{Discussão}

Todas as crianças participantes, consoantes com suas particularidades, revelaram algum grau de impacto em suas vidas, suscitado pelo adoecimento físico e decorrente internação. Ao relatarem sensações corporais atípicas e perda de controle de partes ou funções do corpo, mostraram experimentar os sintomas como um registro de ameaça real a sua integridade física e psíquica. Somou-se a isso, a experiência de internação, vista como restritiva e punitiva, percebendo-se impotentes e desapropriadas de sua autonomia. A literatura tem apontado esses aspectos marcantes do adoecer na vida da criança enferma (Castro, 2007; Nigro, 2004; Ribeiro \& Pinto Junior, 2009). Para além da atual experiência, as crianças com diagnóstico precoce de doença orgânica crônica (C2, C4 e C5) também trouxeram sentimentos relacionados aos cuidados e restrições presentes em suas rotinas devido a limitações impostas pela condição de cronicidade. Essa questão também esteve presente nos estudos de Anton e Piccinini (2011), Aquino, Conti e Pedrosa (2014) e Mello e Moreira (2010), que apontaram implicações físicas, emocionais e sociais de diagnósticos de doenças crônicas na perspectiva das crianças. C5 revelou medo e frustração associados ao diagnóstico de Lúpus Eritematoso Sistêmico ao verbalizar e representar em seu desenho-estória sua percepção de ser diferente das demais crianças e seu temor pela morte. Parece, com isso, compreender sua doença e internação como perda ou castigo, situação que foi descrita amplamente por Aberastury (1984). C4 também expressou, no desenho-estória, sentimento de culpa por sua mãe estar sofrendo por sua enfermidade, sugerindo fantasia onipotente de ser responsável pelo seu sofrimento.

A compreensão que a criança tem de sua doença e tratamento é um dos fatores importantes para a sua adaptação e aceitação dos cuidados hospitalares. Elas mencionaram, em algum grau, informações referentes a seus diagnósticos e tratamento e demonstraram interesse nas informações clínicas. Algumas crianças mostraram compreender mais objetivamente sua doença e gravidade e perceberam a possibilidade de suas condutas facilitarem seu processo de recuperação, ao passo que outras apoiaram suas percepções dos sintomas em algo direto e evidente (vê, sente), e perceberam a doença como processo que vitimiza ou invade. Diante disso, Barros (2014) assinala que existem crianças que assumem significações características de diferentes níveis quando em vigência ativa da doença, decorrente de condição emocional em relação ao adoecimento, influências familiares e culturais. As crianças recordaram informações, enquanto outras foram esquecidas, podendo indicar, com isso, resistências diante de certas notícias, quando escutam o que suas condições emocionais permitem assimilar no momento (Gabarra \& Crepaldi, 2011). A linguagem médica também pode dificultar a assimilação pelo uso de termos técnicos de difícil compreensão para as crianças (Perosa et al., 
2006), o que pode ter ocorrido com as crianças do presente estudo, que verbalizaram não compreender algumas informações transmitidas por esses profissionais.

Mesmo quando têm informações concretas sobre sua condição de saúde, as crianças utilizam a fantasia para enfrentar $\mathrm{O}$ adoecer (Aberastury, 1984). Esse recurso foi observado nas crianças, especialmente em seus desenhos-estórias. Aqui, surgiu como mecanismo para a integridade do ego, possibilitando à criança dar significado e lidar com a nova realidade (Lepri, 2008). Os desenhos-estórias permitiram às crianças ilustrarem sentimentos referentes ao adoecimento, à internação e às relações estabelecidas nesse meio, expressando sua criatividade e projeções, ilustrando personagens com sintomas semelhantes aos seus e, por vezes, "ensaiando" a cessação destes. Diante disso, sugere-se que esse instrumento pode desempenhar um papel terapêutico, auxiliando no manejo das dificuldades advindas da experiência de adoecimento e tratamento, aspecto observado em estudos que o utilizaram (Broering \& Crepaldi, 2013; Martão, 2013; Prudenciatti, Tavano \& Neme, 2013).

Contudo, ressalta-se que a experiência de internação não foi vista pelas crianças somente em seus aspectos negativos, mas também se mostrou revestida de possibilidade de brincar e se relacionar aliada a se tratar. Algumas crianças expressaram desejo e necessidade de brincar para se adaptar e elaborar as exigências e restrições do adoecimento e da internação. Ao brincar, a criança pode representar simbolicamente suas ansiedades, angústias, fantasias e defesas, e controlar os temores que povoam seu mundo interno, projetando-os no exterior (Klein, 1926/1981). O brincar é o meio pelo qual se torna possível para a criança integrar aspectos dissociados dentro de si e possibilitar uma experiência de viver seu verdadeiro eu, usufruindo da espontaneidade e da capacidade criativa (Winnicott, 1975). Hostert, Enumo e Loss (2014) e Lopes, Oliveira Junior e Oliveira (2015) evidenciaram a importância dessa atividade durante o tratamento hospitalar da criança, ao salientarem os brinquedos como veículos de elaboração dessa vivência e a sala de brinquedos como espaço privilegiado identificado pela criança. Já Mello e Moreira (2010) assinalam que o brincar pode ser uma ferramenta facilitadora no estabelecimento de vínculo de confiança entre a criança, o serviço de saúde e seus profissionais. $\mathrm{Na}$ internação, as crianças também demonstraram interesse pelos seus iguais, identificando-se e relacionando-se com outras crianças que vivenciavam situações semelhantes, como C5 e C6, o que representa um aspecto saudável construído nessa experiência. $\mathrm{Na}$ faixa etária estudada, espera-se que passem a desenvolver relações interpessoais mais elaboradas, pautadas em maiores trocas consensuais e cooperação (Ferreira \& Araújo, 2012; Souza, 2014).

Com os relatos e desenhos-estórias, as crianças participantes comunicaram como vivenciaram a relação paciente-médico-cuidador na internação. Mostraram perceber os médicos como responsáveis pelo tratamento de suas enfermidades, porém apontaram a constante transição dos profissionais que as assistiram 
durante internação, sinalizando situação típica de um hospital-escola. Ao se traçar um paralelo com o processo de desenvolvimento do bebê, essa experiência de trocas pode dificultar o estabelecimento de vínculo entre a criança e o profissional diante da não manutenção da confiança na sequência, na estabilidade e na segurança de alguém que esteja com ela (Winnicott, 1968/1999). A maneira como o profissional colabora com a criança, atentando para a empatia, a assertividade e a validação de experiências e sentimentos, contribui para a construção de uma adequada relação terapêutica e para a aderência ao tratamento pela criança (Barletta, Gennari \& Cipolotti, 2011; Crenshaw \& Kenney-Noziska, 2014; Kohlsdorf \& Costa Junior, 2013). Para isso, torna-se necessário a criança reconhecer a disposição do profissional para ajudá-la e compreender as intervenções como úteis para tratar seus sintomas.

Nessa relação, a comunicação entre as partes se mostra fundamental para conduzir a criança a participar ativamente de seu tratamento e a mudar seu estilo de vida (Kohlsdorf \& Costa Junior, 2013, 2016). Todavia, algumas crianças participantes apontaram não terem sido incluídas em situações de comunicação de aspectos do diagnóstico e tratamento, conforme também apontado pelos estudos de Cristo e Araújo (2015) e Kohlsdorf e Costa Junior (2016). A literatura tem evidenciado que, por vezes, o médico estabelece uma relação com a criança regulada pelo afeto e com poucas trocas de informações e tomada de decisões em seu processo de cuidado (Gabarra \& Crepaldi, 2011). Quando a comunicação ocorre entre médico e cuidador/pais, pode refletir uma dificuldade em abordar as crianças verbalmente, perpassada pela ideia de que possam não compreender as explicações ou por uma tentativa de protegê-las dos efeitos psicossociais que o adoecimento possa vir a acarretar em sua vida (Perosa et al., 2006).

A participação e posicionamento dos pais em relação ao adoecimento e tratamento do filho apresenta especial importância em seu processo terapêutico (Perosa et al., 2006). Neste estudo, a mãe foi vista pelas crianças como a principal cuidadora na internação, e se revelou como relevante figura na relação criançamédico-cuidador. A figura materna apareceu como importante moderadora nessa relação, ao auxiliar o filho em sua apropriação da nova realidade, permeada pela doença e pelo hospital. Foi apontada como principal informante de aspectos do diagnóstico, internação e orientações de cuidados, esclarecendo ou reforçando informações transmitidas pelo médico. Esse resultado foi ao encontro do evidenciado por Gabarra e Crepaldi (2011), em estudo que descreveu a comunicação médicopaciente-família na perspectiva de 15 crianças hospitalizadas, de 5 a 13 anos, com diagnósticos de doenças crônicas. As autoras apontaram que as mães podem ser colocadas nessa função por terem mais acesso às informações, visto que acompanham de perto o tratamento e a internação dos filhos.

A compreensão dessa experiência possibilitou esclarecimentos a respeito do lugar ocupado pelas crianças nessa relação. Elas tenderam a se mostrar passivas e espectadoras da relação e em seu processo de cuidado. 
Resultado semelhante foi encontrado em estudos pregressos envolvendo doenças crônicas, mostrando que as crianças crescem assistindo à relação dos médicos com suas mães e, em etapa mais tardia do desenvolvimento, por conseguinte, não conseguem se apropriar de seu próprio diagnóstico (Oliveira \& Gomes, 2004).

A mãe também foi percebida pelas crianças como significativa fonte de apoio no enfrentamento de seu adoecimento e tratamento e de suas implicações na rotina de vida. Elas evidenciaram a capacidade materna de holding, conceito postulado por Winnicott (1960/1990), que possibilita um sentimento de realidade e existência, pois a mãe provém as necessidades físicas e emocionais de seu filho, possibilitando um ambiente propício para o seu desenvolvimento. Com o segurar físico e a elaboração psíquica de experiências que transpassam o adoecimento e o tratamento, as crianças têm podido encontrar consolo e conforto nessa figura, o que tem possibilitado suportar o sofrimento e a ansiedade decorrente da atual vivência e diminuir os efeitos adversos do adoecer.

\section{Considerações Finais}

Este estudo possibilitou um melhor entendimento de aspectos da tríade pacientemédico-cuidador, pelo viés da perspectiva da criança hospitalizada sobre o contexto relacional em que se encontra inserida. Os resultados evidenciaram o impacto do adoecimento no psiquismo das crianças e os aspectos negativos e positivos da experiência de internação: vista como restritiva, mas também como espaço de brincar e se relacionar com os pares. As crianças mostraram-se pouco participativas na relação paciente-médico-cuidador, reconhecendo o médico como atuante em seus tratamentos e a mãe, principal cuidadora, como mediadora dessa relação e fonte de informações e apoio psicológico. Tendo em vista os resultados, assinala-se a importância de uma maior inclusão da criança nessa relação, para que possa participar de maneira ativa e colaborativa em sua recuperação, na medida em que entende o sentido dos procedimentos, limitações ou restrições do tratamento.

Embora tenha contribuído para a compreensão das vivências subjetivas das crianças, contemplando a dinâmica relacional no setting pediátrico, algumas limitações podem ser apontadas, tais como a falta de um elemento observacional das interações que se estabeleceram nesse âmbito, e a não inclusão dos demais componentes - médico e cuidador na coleta de dados, para maior abrangência na compreensão do fenômeno.

A partir desses resultados, verifica-se a necessidade de novas pesquisas que auxiliem a compreender outros aspectos implicados na relação paciente-médico-cuidador, para além dos identificados. Investigações futuras poderiam aprofundar a compreensão da relação entre as variáveis aqui estudadas com as crianças, ampliando o escopo de análise e utilizando outras metodologias. Sugere-se também que novas questões sejam pensadas, considerando a possibilidade de um acompanhamento longitudinal, incluindo os demais componentes dessa tríade, para examinar eventuais mudanças em sua dinâmica no decorrer do tempo. 
Destaca-se que os achados deste estudo podem ter repercussões para a prática profissional, é necessária uma intervenção psicossocial e multiprofissional com essas crianças e suas famílias para fortalecer o vínculo com a equipe de saúde. A detecção de eventuais problemas relacionais em cada caso permitirá o encaminhamento precoce, contribuindo para a saúde do paciente infantil e de sua família. Nesse intuito, atividades de educação continuada poderiam contribuir para aumentar a sensibilidade dos profissionais com relação a essa temática.

\section{Referências}

Aberastury, A. (1984). A percepção da morte na criança e outros escritos. (M. N. Folberg, Trad.). Porto Alegre: Artes Médicas.

Aiello-Vaisberg, T. M. J. (1997). Investigação de representações sociais. In W. Trinca (Org.). Formas de investigação clínica em Psicologia (pp. 255-288). São Paulo: Vetor.

Aiello-Vaisberg, T. M. J., \& Ambrósio, F. F. (2013). Rabiscando desenhos-estórias com tema: pesquisa psicanalítica de imaginários coletivos. In W. Trinca (Org.). Procedimento de desenhos-estórias: formas derivadas, desenvolvimentos e expansões (pp. 277-302). São Paulo: Vetor.

Anton, M. C., \& Piccinini, C. A. (2011). O desenvolvimento emocional em crianças submetidas a transplante hepático. Estudos de Psicologia (Natal), 16(1), 39-47.

Aquino, A. M., Conti, L., \& Pedrosa, A. (2014). Construções de significados acerca do adoecimento e morte nas narrativas de crianças com câncer. Psicologia: Reflexão e Crítica, 27(3), 599-606.

Barletta, J. B., Gennari, M. S., \& Cipolotti, R. (2011). A perspectiva cognitivocomportamental dos aspectos psicossociais que interferem na qualidade da relação médico-paciente. Psicologia em Revista, 17(3), 396-413.

Barros, L. (2014). A Psicologia Pediátrica: uma perspectiva desenvolvimentista. Lisboa: Climepsi Editores.

Broering, C. V., \& Crepaldi, M. A. (2013). Psychological Preparation for Surgery: Verbal Report of the Drawing-Story. Estudos de Psicologia (Campinas), 30(3), 367374.

Castro, E. K. (2007). Psicologia Pediátrica: a atenção à criança e ao adolescente com problemas de saúde. Psicologia: Ciência e Profissão, 27(3), 396-405.

Castro, E. K., \& Thomas, C. V. (2012). Parentalidade no contexto da doença crônica infantil. In C. A Piccinini, \& P. Alvarenga (Orgs.). Maternidade e paternidade: a parentalidade em diferentes contextos. São Paulo: Casa do Psicólogo.

Corbett, E., Ambrosio, F. F., Gallo-Belluzzo, S. R., \& Aiello Vaisberg, T. M. J. (2014). Produções imaginativas sobre dificuldades sexuais: um estudo psicanalítico. Psicologia \& Sociedade, 26(3), 756-765.

Crenshaw, D. A. \& Kenney-Noziska, S. (2014). Therapeutic Presence in Play Therapy. International Journal of Play Therapy, 23(1), 31-43.

Creswell, J. W. (2010). Projeto de pesquisa: métodos qualitativo, quantitativo e misto (M. Lopes, Trad.). Porto Alegre: Artmed.

Cristo, L. M. O., \& Araújo, T. C. C. F. (2013). Comunicação em saúde da criança: estudo sobre a percepção de pediatras em diferentes níveis assistenciais. Revista Psicologia e Saúde, 5(1), 59-68.

Cristo, L. M. O., \& Araújo, T. C. C. F. (2015). Comunicação criança-acompanhantepediatra: estudo observacional em diferentes níveis de assistência. Psicologia: teoria e prática, 17(3), 89-103.

Ferreira, M. H. M., \& Araújo, M. S. A. (2012). Idade escolar: latência (6 a 12 anos). C. L. Eizirik, F. Kapczinski \& A. M. S. Bassols 
(Orgs.). O ciclo da vida humana: uma perspectiva psicodinâmica (pp. 105-116). Porto Alegre: Artmed.

Freud, S. (2016). Os três ensaios sobre a teoria da sexualidade (P. C. Souza, Trad.). São Paulo: Companhia das Letras. (Obra original publicada em 1905).

Freud, S. (2011). Introdução ao narcisismo. In S. Freud. Introducão ao narcisismo, ensaios de metapsicologia e outros textos [1914-1916] (pp. 9-37, P. C. Souza, Trad.). São Paulo: Companhia das Letras. (Obra original publicada em 1914).

Gabarra, L. M., \& Crepaldi, M. A. (2011). A comunicação médico-paciente pediátricofamília na perspectiva da criança. Psicologia Argumento, 29(65), 209-218.

Hostert, P. C. C. P., Enumo, S. R. F., \& Loss, A. B. M. (2014). Brincar e problemas de comportamento de crianças com câncer de classes hospitalares. Psicologia: teoria e prática, 16(1), 127-140.

Klein, M. (1981). Psicanálise da criança (P. Ci, Trad.). São Paulo: Mestre Jou. (Obra original publicada em 1926).

Kohlsdorf, M., \& Costa Junior, A. L. (2013). Comunicação em Pediatria: revisão sistemática de literatura. Estudos de Psicologia (Campinas), 30(4), 539-552.

Kohlsdorf, M., \& Costa Junior, A. L. (2016). Comunicação triádica em Pediatria: revisão de literatura. Temas em Psicologia, Ribeirão Preto, 24(2), 609-629.

Laville, C., \& Dionne, J. (1999). A construção do saber: Manual de metodologia de pesquisa em Ciências Humanas (H. Monteiro \& F. Settineri, Trad.). Porto Alegre: Artes Médicas.

Lepri, P. M. F. (2008). A criança e a doença: da fantasia à realidade. Revista da $S B P H$, 11(2), 15-26

Lopes, B. A., Oliveira Junior, C. R., \& Oliveira, V. B. (2015). O brincar como instrumento de resgate do cotidiano da criança hospitalizada. Boletim - Academia Paulista de Psicologia, 35(88), 93-108.
Martão, M. I. S. (2013). D-E com Tema: pesquisas realizadas. In W. Trinca (Org.). Procedimento de desenhos-estórias: formas derivadas, desenvolvimentos e expansões (pp. 303-337). São Paulo: Vetor.

Mello, D. B. de, \& Moreira, M. C. N. (2010). A hospitalização e o adoecimento pela perspectiva de crianças e jovens portadores de fibrose cística e osteogênese imperfeita. Ciência \& Saúde Coletiva, 15(2), 453-461.

Menezes, M., Moré, C. L. O. O., \& Cruz, R. M. (2008). O desenho como instrumento de medida de processos psicológicos em crianças hospitalizadas. Avaliação Psicológica, 7(2), 189-198.

Nigro, M. (2004). Hospitalização: o impacto na criança, no adolescente e no psicólogo hospitalar. São Paulo: Casa do Psicólogo.

Oliveira, V. Z., \& Gomes, W. (2004). Comunicação médico-paciente e adesão ao tratamento em adolescentes portadores de doenças orgânicas crônicas. Estudos de Psicologia (Natal), 9(3), 459-469.

Perosa, G. B., Gabarra, L. M., Bossolan, R. P., Ranzani, P. M., \& Pereira, V. M. (2006). Aspectos psicológicos na comunicação médico-paciente no setting pediátrico. In M. A. Crepaldi \& M. B. M. Linhares (Orgs.). Temas em Psicologia Pediátrica (pp. 57-82). São Paulo: Casa do Psicólogo.

Prudenciatti, S. M., Tavano, L. D., \& Neme, C. M. B. (2013). O desenho: estória na atenção psicológica a crianças na fase précirúrgica. Boletim-Academia Paulista de Psicologia, 33(85), 276-291.

Ribeiro, C. R., \& Pinto Junior, A. A. A. (2009). Representação social da criança hospitalizada: um estudo por meio do procedimento de desenho-estória com tema. Revista da SBPH, 12(1), 31-56.

Schmidt, E., \& Mata, G. F. (2008). Transferência e iatrogenia na relação médico-paciente. Revista Médica de Minas Gerais, 18(1), 37-40.

Simonetti, A. (2008). Manual de Psicologia Hospitalar: mapa da doença. São Paulo: Casa do Psicólogo. 
Sleath, B. et al. (2012). Communication During Pediatric Asthma Visits and SelfReported Asthma Medication Adherence. Pediatrics, 130(4), 1-7.

Souza, A. S. L. (2014). Re-visitando a latência: reflexões teórico-clínicas sobre os caminhos da sexualidade. Psicologia USP, 25(2), 155-161.

Trinca, W. (1997). Apresentação e aplicação. In W. Trinca, (Org.). Formas de Investigação Clínica em Psicologia (pp. 11-34). São Paulo: Vetor.

Winnicott, D. W. (1975). O brincar e a realidade (J. O. A. Abreu \& V. Nobre, Trad.). Rio de Janeiro: Imago.

Winnicott, D. W. (1990). O ambiente e os processos de maturação (I. C. S. Ortiz, Trad.). Porto Alegre: Artes Médicas. (Obra original publicada em 1960).

Winnicott, D. W. (1999). Os bebês e suas mães (J. L. Camargo, Trad.). São Paulo: Martins Fontes. (Obra original publicada em 1968).

Winnicott, D. W. (2000). A preocupação materna primária. In D. W. Winnicott. Da Pediatria à Psicanálise: obras escolbidas (pp. 399-405, D. Bogomoletz, Trad.). Rio de Janeiro: Imago. (Obra original publicada em 1956).

Recebido em: 28/2/2018

Aprovado em: 8/9/2018 